\title{
Spectral, Thermal and NLO Studies of Ammonium Fluoro Antimonate Crystals
}

\author{
R.Kumuthini ${ }^{1}$, P.Selvarajan ${ }^{2}$, S.Selvaraj ${ }^{1}$ \\ ${ }^{I} P G$ and Research Centre, Department of Physics, MDT Hindu College, Tirunelveli-627010, India \\ ${ }^{2}$ Department of Physics, Aditanar College of Arts and Science, Tiruchendur-628216, India
}

\begin{abstract}
Ammonium fluoro antimonate $\left(\mathrm{NH}_{4}\right)_{3} \mathrm{Sb}_{4} \mathrm{~F}_{15}$ crystals were grown by solution method and various properties of grown crystals were analyzed by various experimental tools. The structural study of the grown crystal was carried out by XRD analysis and crystal structure was identified. The vibrational frequencies of of various group ligands in the crystal have been derived from the Fourier transform infrared (FT-IR) spectrum. The optical transmission of the sample was found by UV-vis-NIR spectral analysis. Second harmonic generation (SHG) efficiency was analyzed for the sample by Kurtz powder technique. TG/DTA studies were carried out for the grown crystal.
\end{abstract}

\section{Introduction}

The complexes of fluoro antimonate show interesting mechanical, electrical and optical properties and these complexes have many applications [1-4]. The potassium fluoro antimonate such as $\mathrm{KSbF}_{4}$ and $\mathrm{K}_{3} \mathrm{Sb}_{4} \mathrm{~F}_{15}$ are observed to be showing interesting properties [5]. Some of the sodium fluoro antimonate crystals such as $\mathrm{NaSbF}_{4}, \mathrm{NaSbF}_{5}, \mathrm{NaSb}_{2} \mathrm{~F}_{7}$ and $\mathrm{Na}_{3} \mathrm{Sb}_{2} \mathrm{~F}_{9}$ have already been grown and studied [6,7]. Using alkali halides, many fluoro antimonate complexes such as $\mathrm{MSbF}_{4}, \mathrm{M}_{2} \mathrm{SbF}_{5}, \mathrm{MSb}_{2} \mathrm{~F}_{7}, \mathrm{MSb}_{3} \mathrm{~F}_{10}, \mathrm{MSb}_{4} \mathrm{~F}_{13}, \mathrm{M}_{2} \mathrm{Sb}_{3} \mathrm{~F}_{11}$ and $\mathrm{M}_{3} \mathrm{Sb}_{4} \mathrm{~F}_{15}$ (where $\mathrm{M}=\mathrm{Na}, \mathrm{K}, \mathrm{Cs}, \mathrm{Rb}$ ) can be prepared [8]. Single crystals of undoped sodium fluoro antimonate $\left(\mathrm{Na}_{3} \mathrm{Sb}_{4} \mathrm{~F}_{15}\right)$ were carried out by Kumuthini et al[9] and copper chloride doped $\mathrm{Na}_{3} \mathrm{Sb}_{4} \mathrm{~F}_{15}$ were also grown and various studies have been carried out[10]. In this work, crystals of ammonium fluoro antimonate $\left(\mathrm{NH}_{4}\right)_{3} \mathrm{Sb}_{4} \mathrm{~F}_{15}$ were grown by solution method with slow evaporation technique and various properties such as structural, optical and thermal properties were studied and herewith the results are reported.

\subsection{Synthesis and growth}

\section{Experimental}

Precursor materials such as ammonium fluoride, antimony trioxide and hydrofluoric acid were procured from MERCK India and used to prepare ammonium fluoro antimonate sample. The solvent used for the growth was double distilled water. The purchased chemicals were dissolved in double distilled water in accordance with the chemical equation as given below.

$$
2 \mathrm{Sb}_{2} \mathrm{O}_{3}+3 \mathrm{NH}_{4} \mathrm{~F}+12 \mathrm{HF} \rightarrow\left(\mathrm{NH}_{4}\right)_{3} \mathrm{Sb}_{4} \mathrm{~F}_{15}+6 \mathrm{H}_{2} \mathrm{O}
$$

Using the precursor chemicals and water, the saturated solution was prepared and it was stirred continuously for three hours using a magnetic stirrer to obtain a homogeneous mixture. Then the solution was filtered twice using an ultra micropore filter paper. The resulting solution was taken in a beaker and kept in a hot water bath to obtain supersaturated solution. Seed crystals were obtained from its supersaturated solution taken in a petri dish at room temperature after a period of 5 days. Good optical quality seed crystals free from defects and inclusions are used for the growth of crystals. Two or three seed crystals were carefully placed in the solution taken in a beaker and the beaker was placed in a constant temperature bath at $305 \mathrm{~K}$. Due to slow evaporation, the seed crystals turned into big-sized crystals. The crystals were harvested after a period of about one month and the photograph of the grown crystals is displayed in figure 1. The obtained crystals of AFA15 are found to be colourless, transparent and non-hygroscopic.

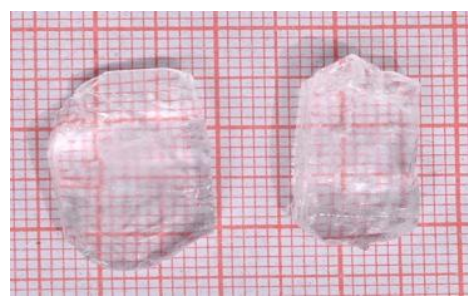

Fig.1: Harvested crystals of ammonium fluoro antimonate $\left(\mathrm{NH}_{4}\right)_{3} \mathrm{Sb}_{4} \mathrm{~F}_{15}$ 


\subsection{Experimental tools}

TG/DTA thermal curves of the sample were recorded using a Perkin Elmer thermal analyzer in nitrogen atmosphere at a heating range of $25^{\circ} \mathrm{C}$ to $700^{\circ} \mathrm{C}$. Single crystal XRD data of the sample were obtained to find the lattice dimensions using ENRAF NONIUS CAD-4 X-ray diffractometer with $\operatorname{MoK}_{\alpha}(\lambda=0.71069 \mathrm{~A})$ radiation. Fourier Transform Infrared (FTIR) technique is the most useful for identifying functional groups of a compound and the FTIR spectrum of $\left(\mathrm{NH}_{4}\right)_{3} \mathrm{Sb}_{4} \mathrm{~F}_{15}$ crystal was recorded using a Perkin-Elmer FT-IR spectrometer using $\mathrm{KBr}$ pellet technique in the range $4000-400 \mathrm{~cm}^{-1}$. To confirm the nonlinear spectroscopy, Kurtz and perry powder SHG test was carried out for the powdered sample using Nd:YAG Q-switched laser which emits the first harmonic output 1064nm[11]. The optical absorption spectrum of the grown crystal has been recorded in the region 220-1200nm using a Perkin Elmer (Model:Lambda 35) UV-vis-NIR spectrophotometer.

\subsection{FTIR spectral analysis}

\section{Results and Discussion}

The FTIR spectrum of $\left(\mathrm{NH}_{4}\right)_{3} \mathrm{Sb}_{4} \mathrm{~F}_{15}$ crystal was recorded using a Perkin-Elmer FT-IR spectrometer using $\mathrm{KBr}$ pellet technique in the range $4000-400 \mathrm{~cm}^{-1}$ and it is presented in the figure 2 . The broad vibrational band observed around $3575 \mathrm{~cm}^{-1}$ is attributed to asymmetric $\mathrm{OH}$ stretching mode of adsorbed water molecule in the sample. The band noticed around $1619 \mathrm{~cm}^{-1}$ is assigned to the bending vibration of water molecules. The FTIR assignments for the absorption peaks/bands of the sample are given in the table 1.

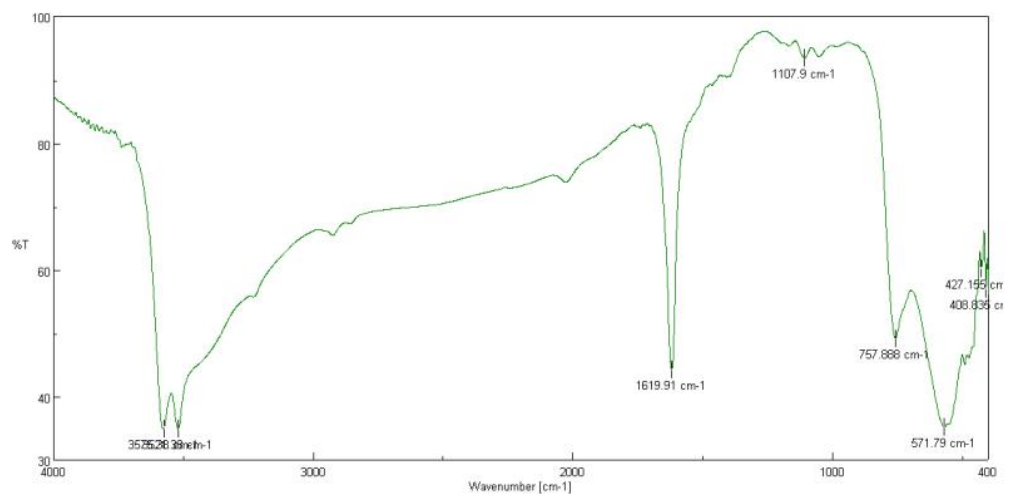

Fig.2: FTIR spectrum of ammonium fluoro antimonate crystal

Table 1: Infrared spectral assignments for ammonium fluoro antimonate crystal

\begin{tabular}{|c|l|}
\hline Wave number $\left(\mathbf{c m}^{-1}\right)$ & \multicolumn{1}{|c|}{ Assignments } \\
\hline 3575.28 & O-H stretching mode of adsorbed water molecule \\
1619.91 & O-H bending mode \\
757.888 & Sb-F vibration \\
571.79 & Sb-F bending mode \\
\hline
\end{tabular}

\subsection{Crystal structure}

Single crystal X-ray diffraction analysis was carried out to determine the lattice parameters of ammonium fluoro antimonate crystal. The lattice parameters and hence the structure were obtained for the sample using a ENRAF NONIUS CAD4 X-ray diffractometer with $\operatorname{MoK}_{\alpha}$ radiation $(\lambda=0.71069 \AA)$. The obtained lattice parameters for the sample are $a=7.928(3) \AA, b=6.821(4) \AA, c=15.253(2) \AA, \alpha=90^{\circ}, \beta$ $=103.57^{\circ}, \gamma=90^{\circ}$. It is observed that ammonium fluoro antimonate crystals belong to monoclinic system, with the number of molecules per unit cell $\mathrm{Z}=2$. The volume of monoclinic unit cell is found from the relation $\mathrm{V}=\mathrm{a}$ b c $\sin \beta$ and the obtained value is $801.81(3) \AA^{3}$. The space group of the system is $\mathrm{P} 2_{1}$ and it is recognized as noncentrosymmetric, thus satisfying one of the basic and essential material requirements for the SHG activity of the crystal.

\subsection{Second Harmonic Generation (SHG)}

Second harmonic generation (SHG) is a nonlinear optical process that results in the conversion of an input optical wave into an output wave of twice the input frequency. The light propagated through a crystalline solid, which lacks a centre of symmetry, generates light at second and higher harmonics of the applied frequency. Such frequency doubling processes are commonly used to produce green light $(532 \mathrm{~nm})$ from, for National Conference on Current Advancements in Physics $3^{\text {rd }} \& 4^{\text {th }}$ February $2017 \quad 2$ | Page Department of Physics, St. John's College, Palayamkottai-627 002, Tamilnadu, India. DOI 10.9790/4861-17002030104 
example, a Nd:YAG (Yttrium-Aluminium-Garnet) laser operating at $1064 \mathrm{~nm}$. The Kurtz powder technique is a convenient method for screening large number of powdered materials for the second order NLO activity without needing to grow large single crystals. The grown crystals were ground to powder of grain size $150 \mathrm{~nm}-200 \mu \mathrm{m}$ and the SHG was confirmed by the emission of green radiation $(532 \mathrm{~nm})$ which was detected by a photomultiplier tube. In this work, Potassium Dihydrogen Phosphate (KDP) was used as the reference material. The value of SHG relative efficiency of ammonium fluoro antimonate crystal is 1.45 times that of KDP.

\subsection{Absorption spectral studies}

Optical absorption spectrum for grown crystal of $\left(\mathrm{NH}_{4}\right)_{3} \mathrm{Sb}_{4} \mathrm{~F}_{15}$ crystal and the absorption of ultraviolet and visible light by molecules causes an electronic transition. Valence electrons can be found in one of the three electron orbitals namely single bonding $\sigma$ orbitals, double or triple bonding $\pi$ orbitals and non-bonding $n$ orbitals of lone pair electrons as in oxygen, nitrogen and halogens. When electromagnetic radiation of the correct frequency is absorbed, a transition takes place to one of the empty anti-bonding orbitals such as $\sigma^{*}, \pi^{*}$ and $n^{*}$ orbitals. Important transitions are $\pi \rightarrow \pi^{*}, n \rightarrow \pi^{*}$ or $n \rightarrow \sigma^{*}$ as these are the only transitions recorded by the spectrometers operating in the range $190 \mathrm{~nm}$ to $1100 \mathrm{~nm}[12,13]$. The recorded absorption spectrum for the sample is shown in the figure 3. The lower cut-off wavelength in the UV region is observed to be at $360 \mathrm{~nm}$. As there is no significant absorption in the visible region of the spectrum, this sample can be used as the second harmonic frequency generator.

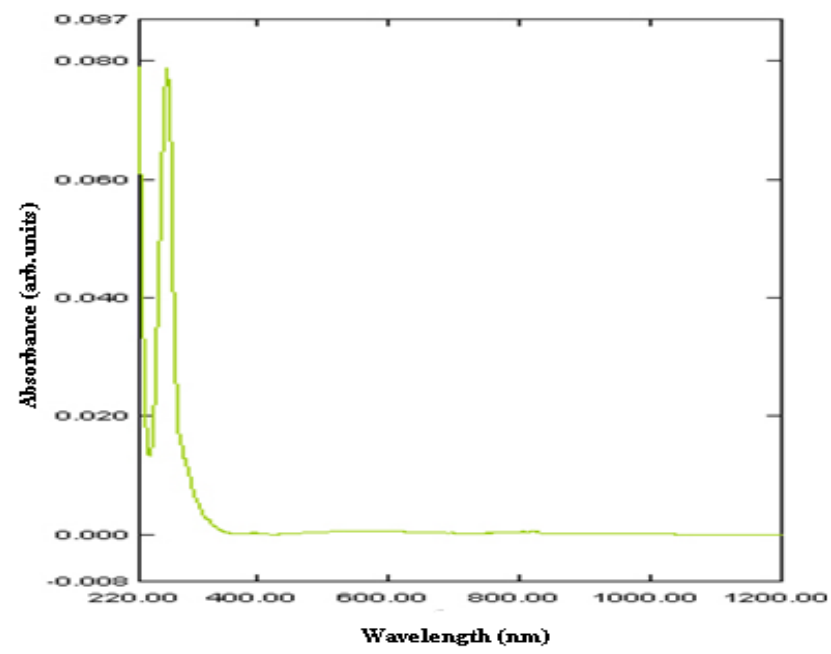

Fig.3: UV-visible absorption spectrum of $\left(\mathrm{NH}_{4}\right)_{3} \mathrm{Sb}_{4} \mathrm{~F}_{15}$ crystal

\subsection{Thermal studies}

Thermal studies involve the measurements of various properties of materials under predetermined conditions of heating rate, temperature range and gaseous atmosphere or vacuum. Though a variety of thermal analysis techniques exists, the most commonly used techniques are thermogravimetric (TG) analysis and differential thermal analysis (DTA). Generally, instead of using a single technique, combinations are used to access complete and complementary information to facilitate thermal analysis of materials like thermal stability, material parity and determination of water, carbonate and organic content $[14,15]$. TG/DTA thermal curves for $\left(\mathrm{NH}_{4}\right)_{3} \mathrm{Sb}_{4} \mathrm{~F}_{15}$ crystal were recorded using a Perkin Elmer TG/DTA analyser at a heating rate of $10{ }^{\circ} \mathrm{C} / \mathrm{min}$ in nitrogen atmosphere for the temperature range of $30{ }^{\circ} \mathrm{C}$ to $700{ }^{\circ} \mathrm{C}$ and it is presented in the figure 4 . The presence of adsorbed water in the crystal of $\left(\mathrm{NH}_{4}\right)_{3} \mathrm{Sb}_{4} \mathrm{~F}_{15}$ is indicated by an endothermic peak at $54{ }^{\circ} \mathrm{C}$. There is a weight loss $(54 \%)$ is observed from $200{ }^{\circ} \mathrm{C}$ to $400{ }^{\circ} \mathrm{C}$ and the endothermic peak at $221{ }^{\circ} \mathrm{C}$ corresponds to the decomposition point of the sample. An additional weight loss $(25 \%)$ is observed form $400{ }^{\circ} \mathrm{C}$ to $700{ }^{\circ} \mathrm{C}$. At elevated temperatures this decomposition process continues and the residue obtained is about 5 weight $\%$ of the sample. The thermal stability of $\left(\mathrm{NH}_{4}\right)_{3} \mathrm{Sb}_{4} \mathrm{~F}_{15}$ crystal upto $221{ }^{\circ} \mathrm{C}$ confirms its probable application in the NLO device fabrication. 


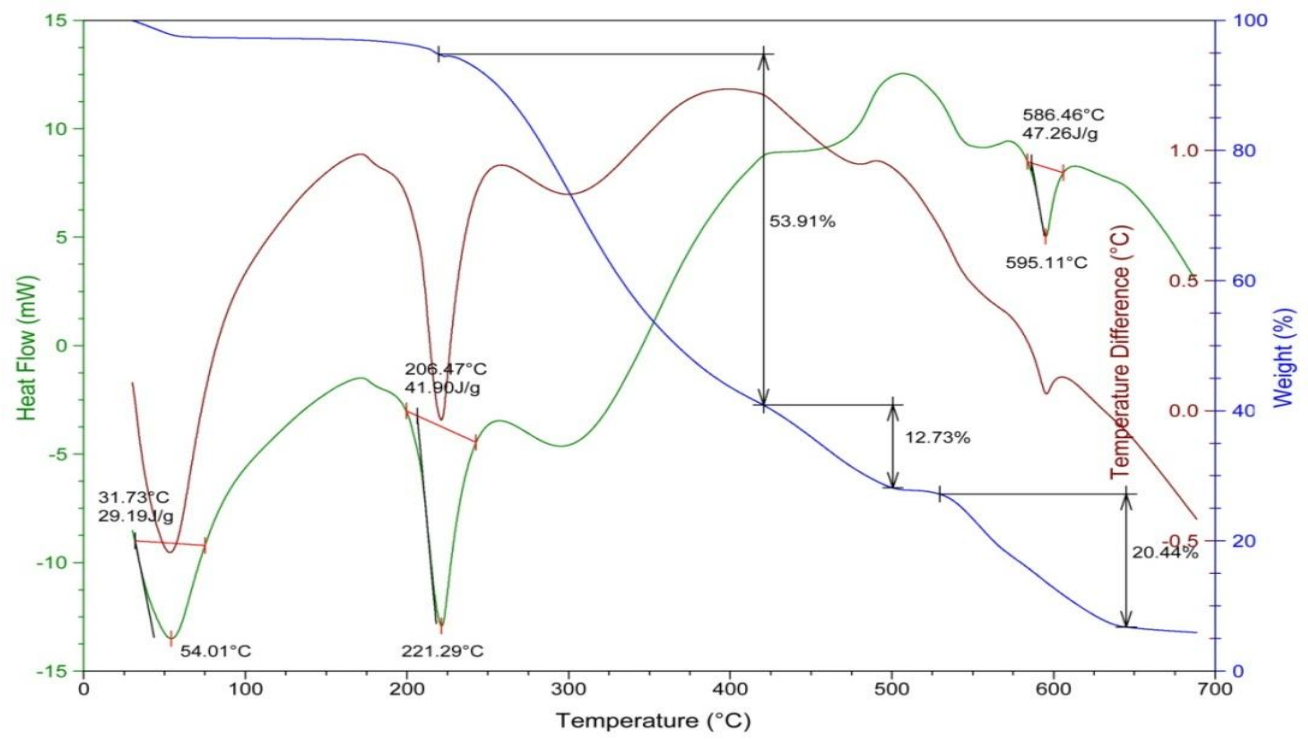

Fig.4: TG/DTA curves for $\left(\mathrm{NH}_{4}\right)_{3} \mathrm{Sb}_{4} \mathrm{~F}_{15}$ crystal

\section{Conclusion}

Crystals of Ammonium fluoro antimonate $\left(\mathrm{NH}_{4}\right)_{3} \mathrm{Sb}_{4} \mathrm{~F}_{15}$ were grown by solution method. The functional groups of the samples have been found by FTIR analysis. The thermal stability of $\left(\mathrm{NH}_{4}\right)_{3} \mathrm{Sb}_{4} \mathrm{~F}_{15}$ crystal is about $221^{\circ} \mathrm{C}$. The crystal structure of the grown crystal is found to be monoclinic. The results show that the grown crystal has very low absorbance in the visible region.

\section{Acknowledgement}

The supportive works from Madras University (Chennai), M.K.U University (Madurai), P.S.N Engineering college (Tirunelveli), Crescent Engineering college (Chennai) and Pondicherry University were gratefully acknowledged. The authors would like to thank the management of Aditanar College of Arts and Science, Tiruchendur and M.D.T Hindu College, for the encouragement and support given to us to carry out this research work.

\section{References}

[1] R.Rani Christu Dhas, J.Benet Charles, F.D.Gnanam, Journal of Crys. Growth, 137(1994)295.

[2] J.G.Bergman, D.S.Chemla, R.Fourcade and G.Mascherba, J.Solid State Chem., 23(1978) 187.

[3] F.B.Kalinchenko, M.P.Borzenkova and A.V.Novoselova, Russ.J.Inorg.Chem., 27(1982)1653.

[4] M.B.Ducourant, B.Bonnet, R.Fourcade and G.Mascherba, Bull.Soc.Chem., 8(1975) 1471.

[5] M.V.Borzenkova, F.V.Kalinchenko, A.V.Novoselova, A.K.Ivanovshits and N.I.Sorokin, Russ.J.Inorg.chem., 29 (1984) 405.

[6] J.Benet Charles and F.D.Gnanam, Cryst.Res.Technol., 29 (1994) 707.

[7] J.Benet Charles and F.D.Gnanam, Cryst.Res.Technol., 25 (1990) 1063.

[8] L.A.Zemnukhova, E.V.Kovaleva, G.A.Fedorischeva, V.V.Kon'shin, R.L.Davidovich, Russ. J. Coord. Chem., 30(2004)833

[9] R.Kumuthini, P.Selvarajan, S.Selvaraj, Int Journal of Innovative Res in Adv Engg 2 (2015) 49.

[10] R.Kumuthini, P.Selvarajan, S.Selvaraj, Int Journal of Innovative Res in Adv Engg 2 (2015) 49.

[11] S.K.Kurtz, T.T.Perry, J Appl phys.39(1968)3798.

[12] K. Pankove, Optical processes in semiconductors, Prentice-Hall, NewYork, (1971).

[13] Hernandez-Paredes, J., Glossman-Mitnik, D., H.E. Esparza-Ponce, H., Alvarez- Ramos,M.E. and A.Duarte-Moller, J.Molecular Structure, 875, 295-301, (2008).

[14] D.Gross and G. Grodsky, J. Am. Chem. Soc., 107, 5921-5927, (1955).

[15] Hernandez-Paredes, J., Glossman-Mitnik, D., Hernandez-Negrete, O., Esparza- Ponce, H., Alvarez R, M.E., and Rodriguez Mijangos. R., J. Physics and Chemistry of Solids, 69, 1974-1979, (2008). 